\title{
Grants scheme struggles ahead
}

Warsaw \& Gdansk

WHEN Witold Karczewski was appointed to head KBN, in Spring 1991, his immediate challenge was to supervise a new western-style system of competitive research grants to individual researchers. After decades of funding by bureaucrats, who poured money into institutes seemingly oblivious of the quality of the work they were supporting, the new system has literally been built from nothing. Not surprisingly, given the flood of applications (around 10,000) in the first grant round, Karczewksi and his colleagues on $\mathrm{KBN}$ admit to teething troubles.

The biggest problem has been finding reviewers to vet the applications. KBN took advantage of the election which defined its membership by asking voters to fill in a brief questionnaire about their own work, which provided the beginnings of a database of referees. But in many disciplines, the size of the Polish scientific community is small - a common complaint is that there are only two or three Polish researchers capable of reviewing a particular grant proposal. Karol Taylor, from the University of Gdansk, and a KBN member responsible for distributing grants in molecular biology, says that most of his outside reviewers were fairly uncritical, presumably because they knew the applicants. In the end, most of the difficult decisions that led to the final molecular biology ranking list were made by a committee of 10 biologists appointed by Taylor to help with the review process.

One solution - at least until Poland's scientists have learned to apply some harsh objectivity to peer review - will be to involve referees from abroad. The US National Science Foundation and the North Atlantic Treaty Organization

is to ensure that KBN's scarce resources are given to the best institutes and researchers in the country. A new system of competitive individual research grants, which struggled to life last year (see above), will help, but Karczewski also intends to be more discriminating when handing out money to Poland's research institutes, which now receive their core budgets from KBN. Under the old system, government spending on research was dominated by large block grants to institutes and laboratories (with little consideration of the quality of research going on inside) rather than awards for specific projects. This was still largely the case for the 1991 science budget, the first handled by $\mathrm{KBN}$, but Karczewski promises changes in 1992.

Karczewski's guide, as he tries to introduce some selectivity into Polish science, is a comprehensive assessment of have offered their referee databases to KBN, but for the committee to employ foreign reviewers, Polish scientists must begin to submit their grant proposals in English. KBN is encouraging applicants to do so, and in fields where Polish science is relatively strong, such as physics, mathematics and neurobiology, many applicants are heeding this request. But Karczewski says it will take time before most Polish researchers, many of whom fear that their work would be viewed as "parochial" by foreign referees, follow suit.

The sheer scale of the first grant round gave $\mathrm{KBN}$ little opportunity to check the validity of many applications. Karczweski says he has exercised his veto over KBN's decisions to block the award of several grants, after reading applications that he was sure were attempts to defraud the committee, rather than genuine research proposals. But as the system settles into a routine of twice-yearly grant rounds, and the number of applications should become more manageable, this problem should ease.

Karczewski's biggest disappointment is that the cuts he was forced to make to the 1991 science budget hit the competitive grant system hardest of all: around $\$ 50$ million was awarded, a quarter of the figure that KBN had planned. (By the time that the budget cuts were announced, most of KBN's other spending had already been committed.) Nevertheless, Karczewski is determined that the competitive grant scheme should grow to become the cornerstone of Polish science funding. He would like grants to consume half of the national science budget, rather than the singlefigure percentage they represented in 1991.

all Poland's research centres - the 80 institutes under the Academy of Sciences, the applied research centres linked to various ministries, and university departments. Karczewski believes that the ranking lists which have now been drawn up - based on the numbers of $\mathrm{PhDs}$ and full professors at each institute, and their publication records - are uncontentious. "Very few people have protested", he says.

This year, Karczewski promises to concentrate funding in centres near the top of the ranking lists. He freely admits that some institutes will be forced to close. But for the time being at least, it seems that scientists employed on basic research have relatively little to fear: most of the institutes of the Academy of Sciences, the bastion of Polish basic research during the Communist era, were rated highly by $\mathrm{KBN}$. And with the committee domi- nated by researchers from the universities (70 per cent of Poland's researchers are based in institutes of higher education), $\mathrm{KBN}$ has an inbuilt sympathy towards basic science.

For industrial researchers, however, the prospect of unemployment is all too real. Jan Krzysztof Frackowiak, undersecretary of state at $\mathrm{KBN}$, is scathing about the quality and relevance of the work in the 150 or so laboratories linked to the industry ministry. Less than 30 per cent of their work has ever been used by Polish industry, he estimates. Karczewski predicts that as many as 30 of these institutes may be shut down in 1992, after their funding from $\mathrm{KBN}$ dries up making several thousand researchers and technicians unemployed, if they cannot find funding from elswhere. Karczewski argues that industrial research should be paid for by its users, rather than by the state. But given the virtual collapse of Polish industry (most of which is, in any case, still state-owned) there is little hope of a new wave of research contracts to reinvigorate Poland's industrial laboratories.

Despite KBN's determination to end state subsidies for sub-standard industrial research, Karczewski would like to identify a number of promising industrial sectors where government support for research could pay dividends. Asked to name some examples, he suggests the production of small aircraft, and medical microelectronics. But at present, Karczewski can do little until the government produces a long term industrial policy. With its resources badly stretched, KBN cannot afford to start picking winners on the industrial scene, only to find that the government chooses a different range of enterprises as worthy of financial aid. It is here that the lack of a strong, stable government will be a problem, although a more serious threat to the reforms planned by KBN seems for the time being to have receded. One possibility, as Poland's centre-right political parties manoeuvered to build a government before Christmas, was that the chairmanship of $\mathrm{KBN}$ (which carries ministerial rank) would be given to a career politician from one of the minor parties, lacking Karczewksi's experience in science policy. But Karczewski and Frackowiak's shrewd strategy of keeping on the sidelines, maintaining friendly relations with all of the major political parties, without seeming to have become too close to any one of them, has been successful, and Karczewksi remains in office.

But the reform of Polish science may be less important to the new Polish parliament than for its predecessor. Most of the academics who entered the Senat and Sejm in 1989 have now returned to research: before the 1991 elections, fully 